\title{
Casos sustentáveis
}

1 sustentabilidade corporativa fincou raízes no Brasil. De fato, uma parcela importante de organizações brasileiras pode ser usada como exemplo de aderência às dimensões da sustentabilidade, como a ambiental, econômica e social. Este artigo compila experiências modelares nesse campo e adiciona uma dimensão extra da sustentabilidade: a gestão de riscos. No conjunto, essas iniciativas servem como guias para outras empresas igualmente preocupadas com o impacto de suas ações.

por Marcelo Caldeira Pedroso FIA

As discussões sobre sustentabilidade e desenvolvimento sustentável vêm chamando a atenção dos governos, empresas e universidades nos últimos anos. Essas organizações estão percebendo que a sustentabilidade não é um modismo empresarial ou um conjunto de ações isoladas visando a melhorar a reputação das empresas. Ao contrário, as organizações estão tomando consciência de que a sustentabilidade é uma necessidade imposta pela sociedade, e vêm incorporando os seus conceitos e princípios na gestão de suas operações, permeando a maioria dos seus processos de negócios. 
A definição tradicional de desenvolvimento sustentável sugere que as organizações devam atender a necessidades do presente sem comprometer a capacidade das gerações futuras em atender a suas próprias necessidades. Paratanto, as organizações que adotam as práticas de sustentabilidade devem amparar-se, simultaneamente, em três pilares: em um pilar ambiental; em um econômico; em um pilar social (videfigura 1); e, acrescentamos neste artigo, em um pilar de gestão de riscos.

Pretendemos apresentar aqui exemplos concretos de organizações brasileiras cujas práticas as destacam em cada um dos pilares da sustentabilidade anteriormente mencionados. Como conclusão, o artigo aponta para a necessidade de al ocação estratégica equilibrada de recursos entre esses quatro pilares da sustentabilidade pelas organizações brasileiras.

Marcos nacionais. Em 1992, o país foi o anfitrião da Conferência das Nações Unidas sobre Meio Ambiente e
Desenvolvimento, conhecida como Rio-92. Este encontro da comunidade mundial gerou a Agenda 21, um documento com diretrizes para a adoção do desenvolvimento sustentável em todos os países. A Agenda 21 Brasileira focou seis temas: agricultura sustentável, cidades sustentáveis, infra-estrutura e integração regional, gestão dos recursos naturais, redução das desigualdades sociais e ciência e tecnologia para o desenvolvimento sustentável.

Além da Rio-92, outros passos importantes foram dados no âmbito nacional. E, neste sentido, o Brasil vem se sobressaindo em al gumas áreas, em particular na agroenergia e na reciclagem. Em 1975, o governo brasileiro criou o Proálcool, um programa nacional com o intuito de promover a substituição da gasolina pelo álcool como combustível dos automóveis. 0 principal objetivo na época foi conter os gastos com a importação do petróleo.

No entanto, hoje ele é considerado como um programa bem-sucedido de utilização da agroenergia. N esta mesma

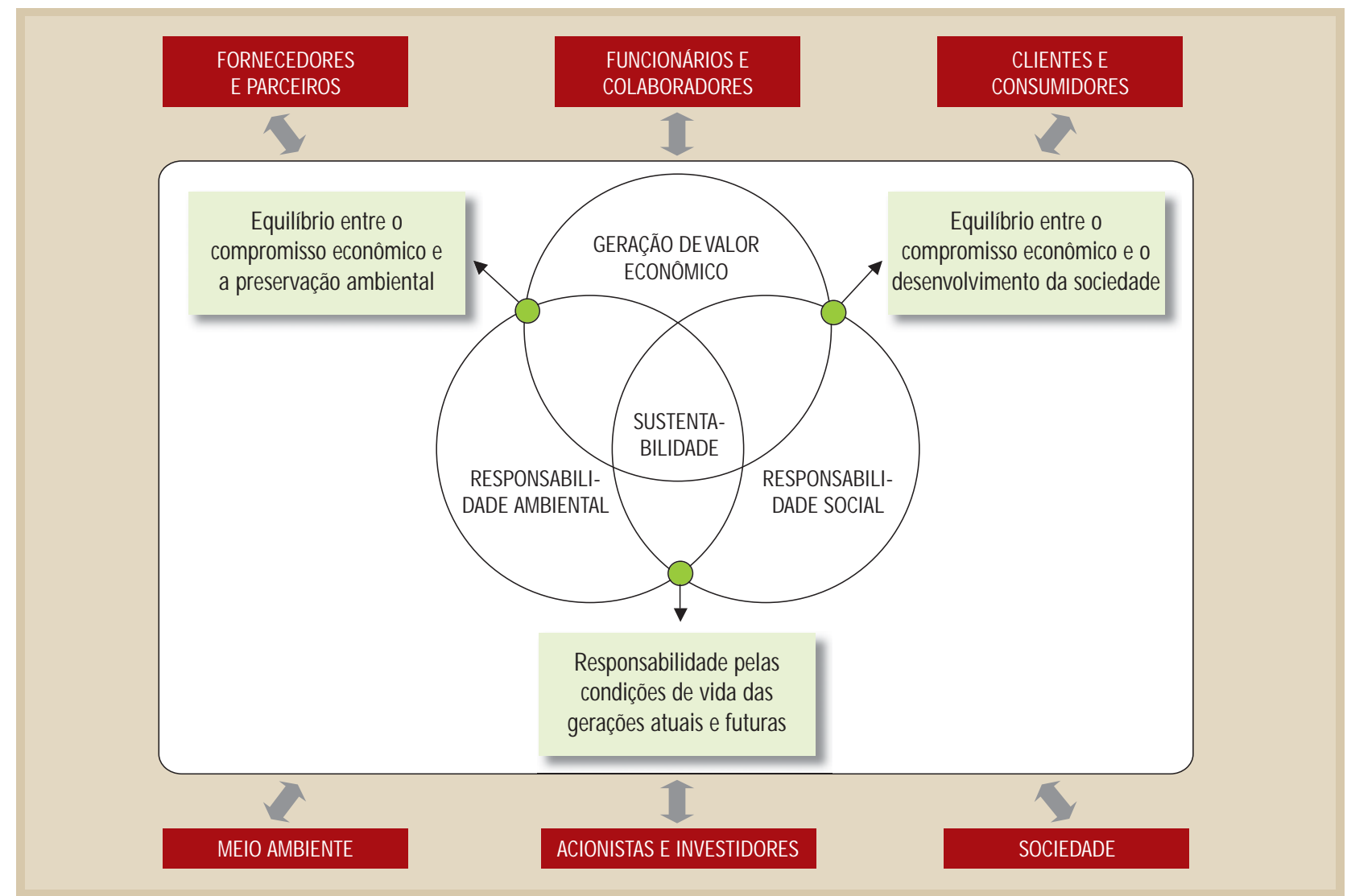

Figura 1: Conceito de sustentabilidade corporativa 
linha, o Brasil vem desenvolvendo o biodiesel como uma alternativa ao diesel tradicional, derivado do petróleo. 0 biodiesel é um combustível natural, produzido através de fontes renováveis, usado em motores movidos a diesel. No Brasil, as empresas geralmente utilizam a soja e a mamona como as principais matérias-primas, podendo ainda utilizar outras fontes vegetais ou animais.

O Brasil ocupa uma posição de destaque mundial em alguns processos de reciclagem. Segundo a Associação Brasileira dos Fabricantes de Latas de Alta Reciclabilidade (Abralatas), em 2005 o país sagrou-se pentacampeão mundial na reciclagem de latas de alumínio para bebidas, com um índice de reciclagem de $96,2 \%$. As embalagens de papelão ondulado também merecem menção, uma vez que apresentam uma taxa atual de reciclagem de $79 \%$, segundo dados da Associação Brasileira do Papelão Ondulado (ABPO).

Sustentabilidade ambiental. No âmbito corporativo, algumas empresas brasileiras vêm sendo citadas como casos mundiais em algumas das dimensões da sustentabilidade. Em 1997, Stuart Hart publicou um artigo na Harvard Business Review que destaca a Aracruz Celulose como uma empresa que adota a visão de desenvolvimento sustentável nas suas operações, ressaltando o modelo de reflorestamento das plantações de eucaliptos.

A Aracruz vem mantendo esse destaque. Ela e a Klabin foram as primeiras empresas brasileiras a aderirem à Bolsa de Carbono de Chicago (ou CCX - Chicago Climate Exchange). Este fato implica que elas assumem metas de redução da emissão de gases de efeito estufa e que podem vender créditos de carbono, que são títulos concedidos às empresas que absorvem mais poluentes do que lançam na atmosfera. Em julho de 2006, a Aracruz, em conjunto com o Banco Itaú e a Cemig, representavam o Brasil na composição do Índice Dow Jones de Sustentabilidade (DJSI World 2005/2006) da Bolsa de Valores de N ova York.

Além da Aracruz, a Klabin também éum exemplo interessante de atuação de uma empresa brasileira na dimensão ambiental da sustentabilidade. A Klabin vem inovando através de algumas iniciativas em gestão ambiental. Por exemplo, em 1998 ela foi a primeira empresa do segmento de papel e celulose nas Américas a ser certificada pelo
Forest Stewardship Council (FSC), que é uma organização internacional que promove a gestão responsável das florestas mundiais.

Sustentabilidade econômica. Já o modelo de negócios das Casas Bahia mostra que é factível às empresas obterem resultados financeiros sustentáveis ao atenderem a população mais necessitada. 0 caso encontrou eco no trabalho influente do professor C. K. Prahalad, traduzido no Brasil como "A riqueza na base da pirâmide". Prahalad considera que as classes menos favorecidas representam um mercado grande, lucrativo e sustentável, desde que as empresas adotem um modelo financeiro adequado.

Outra iniciativa que merece menção é a do Banco do N ordeste. Esta instituição financeira é considerada o maior banco de desenvolvimento regional da América Latina, e ad ota a missão de promover o desenvolvimento sustentável da região Nordeste através do fornecimento de recursos financeiros e suporte à capacitação técnica para empreendimentos regionais. Em 1997, o Banco do N ordeste iniciou um programa denominado CrediAmigo, visando a prover crédito aos pequenos negócios na região. Hoje o CrediAmigo é considerado o maior programa de microcrédito da América do Sul, e vem sendo um instrumento de redução das desigualdades sociais ao promover a inserção dos pequenos empreendedores no mercado.

Sustentabilidade social . A dimensão econômica da sustentabilidade é igualmente acompanhada de uma dimensão social, e, neste caso, algumas empresas brasileiras podem ser citadas. 0 Bradesco, por exemplo. A Fundação Bradesco foi criada por Amador Aguiar, fundador do Bradesco, em 1956, ou seja, em uma época em que o termo sustentabilidade nem sequer aparecia na história. A Fundação Bradesco, cujo lema é "educar é transformar vidas e abrir caminhos", contribui para a responsabilidade social através da educação básica e profissional. Desde então, ela gerou frutos concretos mediante a formação de mais de 600 mil alunos.

Outras empresas brasileiras também atuam com distinção na área de responsabilidade social por meio de instituições a elas vinculadas. Estes são os casos da Fundação 0 debrecht (mantida pela O rganização 0 debrecht), da 
Fundação Itaú Social (ligada ao Itaú), da Fundação Vale do Rio Doce (da Companhia Vale do Rio Doce) e do Instituto Pão de Açúcar de Desenvolvimento Humano (ou IPADH, associado ao Grupo Pão de Açúcar).

Sustentabilidade e riscos. Qualquer empresa está exposta ao risco. Em outras palavras, o risco está na essência dos negócios, e as empresas bem-sucedidas sabem bem como administrá-lo. 0 cenário atual impõe incertezas e variabilidades às empresas, tais como novas regulamentações, pressões competitivas originadas de novos concorrentes e da globalização, alterações nas taxas cambiais e de juros, desenvol vimentos tecnológicos, propagação e acesso rápido às informações através da

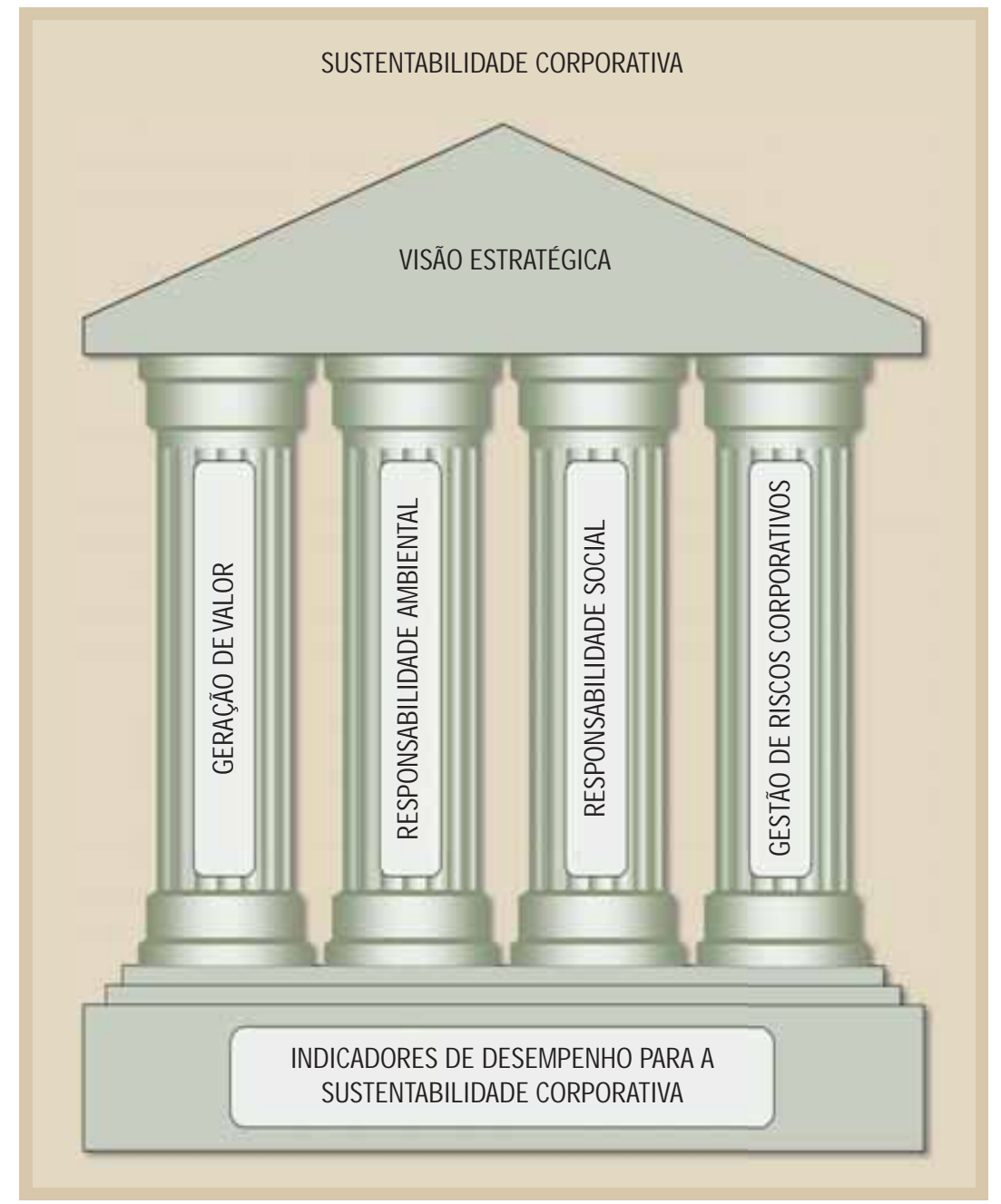

Figura 2: Dimensões da sustentabilidade corporativa tecnologia da informação, além dos efeitos decorrentes de acidentes, atentados e catástrofes naturais.

Assim, é fundamental que as empresas se protejam contra as incertezas e variabilidades do seu ambiente de negócios, visando a garantir a sua perpetuidade, o seu crescimento e a geração de valor aos acionistas, colaboradores, clientes, parceiros de negócios e sociedade em geral. 0 processo de gestão de riscos corporativos atua nestas questões. Ele tem como objetivo identificar e analisar os riscos potenciais relacionados aos negócios da empresa, e apresentar medidas de prevenção e mitigação para os eventos críticos esperados e inesperados.

N este sentido, a perpetuação das operações das organizações é a principal justificativa para se inserir a gestão de riscos corporativos no âmbito da sustentabilidade, ao lado da geração de valor econômico, da responsabilidade ambiental e da responsabilidade social. Essas dimensões são direcionadas pela visão estratégica da empresa, enquanto 0 conjunto de indicadores de desempenho para a sustentabilidade é a base para uma efetiva gestão das ações nesta área (Vide Figura 2).

Em síntese, a sustentabilidade pressupõe que as empresas apresentem resultad os financeiros positivos (através da geração de valor) eque sejam perenes (mediante uma efetiva gestão de riscos corporativos), para que se possam investir recursos na preservação do meio ambiente e no desenvolvimento da sociedade.

Riscos nas corporações brasilei ras. Nas organizações financeiras, os riscos de mercado, os riscos de crédito e os riscos operacionais estão no cerne de suas operações. Sendo assim, geralmente os processos de gestão de riscos são bem maduros nos bancos, seguradoras e empresas de cartões de crédito. No entanto, outras empresas 
de serviços e manufatura também vêm desenvolvendo estes processos.

Por exemplo, a Petrobrás instituiu, em 2004, o Comitê de Gestão de Riscos com o intuito de realizar uma gestão integrada das exposições da empresa aos riscos, bem como definir as diretrizes para lidar com as incertezas inerentes às suas atividades e aproveitar as oportunidades de crescimento. Este comitê gerencia diferentes categorias de riscos, tais como os riscos financeiros, do mercado de petróleo e derivados, cambiais, de taxas de juros e riscos de crédito. Ainda se incluem a gestão de seguros, processos judiciais, contingências e questões ambientais.

Outros exemplos podem ser citados. A empresa de transporte aéreo Gol apresenta um Comitê de Políticas de Risco na sua estrutura de governança corporativa. Este comitê éresponsável por analisar os impactos das variações dos fatores econômicos que podem afetar os seus resultados, tais como o descasamento de moedas entre receitas e custos, e as variações nas taxas de juros e nos custos dos combustíveis de aviação. 0 comitê também avalia as decisões e as medidas adotadas para proteger a empresa contra estas variações, tais como a política de hedge.

A Embraer incorporou a gestão de riscos aos seus processos de planejamento estratégico e operacional buscando a proteção e sustentabilidade de seus negócios. Os principais riscos gerenciados são os estratégicos, os associados às demonstrações financeiras, os econômico-financeiros, além dos riscos do meio ambiente, riscos operacionais e de conformidade.

Equilíbrio nas ações. Certamente as empresas apresentam diferentes tamanhos, valores, missões do negócio, estratégias competitivas, bem como possuem competências distintas e atuam em diferentes mercados. Independente desta questão, todas as organizações podem adotar os princípios da sustentabilidade. Não obstante, a disponibilidade de recursos financeiros, humanos, naturais, tecnológicos, de infra-estrutura e de conhecimento é, em maior ou menor grau, limitada. Desta forma, é fundamental que ocorra um equilíbrio entre os investimentos nas diferentes dimensões da sustentabilidade, e que estas ações estejam alinhadas às prioridades estratégicas definidas pela empresa.
A Natura é um exemplo interessante de atuação com harmonia nas quatro dimensões da sustentabilidade consideradas neste artigo. 0 exemplo na dimensão ambiental considera o lançamento da linha Ekos, em 2000, com produtos que incorporam ativos da biodiversidade brasileira obtidos de forma sustentável. N a dimensão econômica, vale mencionar quea $\mathrm{N}$ atura gerou, em 2004, uma renda superior a R 1 bilhão para as suas consultoras, que atuam através do modelo de distribuição direta de seus produtos.

$\mathrm{Na}$ dimensão social, a Natura possui, desde 1996, um programa denominado "Crer para Ver", no qual os recursos provenientes da venda dos produtos desta linha são investidos na educação. E na dimensão gestão de riscos, a Natura apresenta um sistema de gestão de riscos com foco nos riscos financeiros, de produtos, segurança etecnologia da informação, riscos do meio ambiente e de consistência entre valores e práticas. Estaúltima categoria engloba os riscos relacionados ao comportamento ético, à transparência na informação para os diversos públicos e à adoção de metas empresarias compatíveis com o desenvolvimento sustentável.

País sustentável. Os exemplos apresentados ao longo deste artigo mostram que a sustentabilidade já é uma realidade para as organizações brasileiras. Algumas iniciativas são casos mundiais de sucesso. Dentre as citadas, pode-se destacar o desenvolvimento do biodiesel na agroenergia, o modelo de negócios das Casas Bahia para atender a população de baixa renda, a Fundação Bradesco como um modelo de responsabilidade social que existe há mais de meio século.

Esses exemplos apontam que é viável adotar modelos de negócios que atendam, simultaneamente, os objetivos de agregação devalor, responsabilidade ambiental e responsabilidade social da sustentabilidade. Em nossa visão, eles deveriam servir como parâmetro para outras organizações, visando ao desenvolvimento de um Brasil sustentável.

\footnotetext{
Marcelo Caldeira Pedroso

Doutor em Engenharia de Produção pela POLI-USP

Prof. de MBA na FIA

Consultor de empresas

E-mail: mpedroso@uol.com.br
} 